\title{
Comparison of tools for nutritional assessment in elderly patients:
} A pilot study

\author{
Nesma Gamal Ahmed, MSc ${ }^{1}$, Menna Abdel Ghany Shawkat, MSc ${ }^{1}$, Marian \\ Wagieh Mansour,MSc ${ }^{1}$, Hazem Elsayed Hussien, MSc ${ }^{1}$,Doha Rasheedy, MD ${ }^{2}$.
}

\section{Assistant Lecturer of Geriatrics; Geriatrics and Gerontology Department;} Faculty of Medicine, Ain shams university, Cairo, Egypt.

2 Lecturer of Geriatrics; Geriatrics and Gerontology Department; Faculty of Medicine, Ain shams university, Cairo, Egypt.

Background: Malnutrition is a major health related concern associated with higher morbidity and mortality in the elderly compared to their younger counterparts. Malnutrition is not an inevitable side effect of ageing, but many changes related to ageing can cause malnutrition. The early recognition of patients at high risk of malnutrition is needed to timely manage the condition and avoid its adverse outcomes. Several types of nutrition screening tools have been developed for evaluating the nutritional status of elders; however, the Mini-Nutritional AssessmentShort Form (MNA-SF) is the most widely used tool.

Aim: The aim of this study is to identify the most appropriate nutritional screening tool for use in hospitalized elderly population.

Method: Mini-Nutritional Assessment-Short Form (MNA-SF), Malnutrition Universal Screening Tool (MUST), The Nutritional risk screening (NRS), PatientGenerated Subjective Global Assessment (PG-SGA) and Geriatric nutritional risk index (GNRI) were administered to 20 patients. All patients were 60 years and over.

Results: Using the MNA-SF $12(60 \%)$ of the studied sample were malnourished and 8 (40\%) had normal nutritional status. Tools performance in predicting malnutrition was calculated. The sensitivity was $91 \%, 83 \%, 83 \%$ and $66 \%$ and specificity was $50 \%, 62 \%, 12 \%$ and $75 \%$ with the NRS, MUST, PG-SGA and GNRI, respectively. Combining different pairs of tools

MUST and NRS together had better sensitivity $92.8 \%$ and specificity $66.6 \%$ then 2nd better two tools together is NRS and GNRI with sensitivity $91.6 \%$ and specificity $50 \%$ with accuracy $75 \%$ other tools showed high sensitivity but low specificity as PGSGA with NRS and PGSGA and GNRI.

Conclusion: NRS had the highest sensitivity while GNRI had the highest specificity among different studied assessment tools. MUST and NRS together had better sensitivity but lower specificity than either tool alone. Combining the NRS and GNRI had better sensitivity than GNRI alone and better specificity than NRS alone. We recommend using NRS alone as the optimal screening tool.

Keywords: Malnutrition, elderly nutritional status, nutritional assessment tools

\section{Introduction:}

Malnutrition is a deficiency, excess or imbalance of energy, protein and other nutrients enough to cause adverse effects on body form, function and clinical outcome. ${ }^{(1)}$ 
Screening for this state is justified in the elderly, as it is a frequent cause of morbidity in this population ${ }^{(2)}$; it is associated with poor outcomes (1); simple, reliable, valid and acceptable screening tests are available to detect those who are malnourished or at risk of malnutrition; and there is benefit from nutritional intervention in those identified by screening ${ }^{(3)}$.

Nutritional screening, in its various forms, looks for characteristics associated with nutritional problems so that the individuals identified can undergo full nutrition assessment and possible intervention ${ }^{(4)}$. The tools used need to be quick and simple, acceptable to patients and healthcare workers. Furthermore, it must have good sensitivity for detecting treatable malnutrition; even if the specificity is lower ${ }^{(5)}$.

The most widely used and extensively validated screening tool used by dieticians is the Mini-Nutritional Assessment (MNA). It is also a very useful tool for physicians involved in comprehensive geriatric assessment ${ }^{(6)}$. One advantage of the MNA is that it is applicable to a wide range of elderly patients. It is simple and brief. A shortform version of the MNA has been developed (MNA-SF), and is strongly correlated with total MNA score and is applicable for both community dwelling and hospitalized elderly ${ }^{(6)}$.

The wide spectrum of tools available for nutritional assessment is growing larger. They include GNRI $^{(7)}$, NRS ${ }^{(5)}, \mathrm{MUST}^{(2)}$, and PG-SGA ${ }^{(8)}$.

The current study was designed to identify the most appropriate nutritional screening tool for use in hospitalized elderly population.

\section{Methods:}

\section{Study design:}

A cross sectional study was conducted to compare the accuracy of different widely used nutritional screening tools in a sample of 20 consecutively hospitalized elderly patients. All patients were 60 years and over. The patients were categorized based on MNA SF results into 2 groups those with normal nutritional status (MNA SF score $\geq 11$ ) and those with high risk of malnutrition (MNA SF score <11). The study was carried out in the Geriatrics and Gerontology Department at Ain Shams University Hospital in Cairo Egypt.

\section{Malnutrition screening tools}

MNA SF : ${ }^{(9)}$ The score is derived from six components: reduced food intake in the preceding three months; weight loss during the preceding three months; mobility; psychological stress or acute disease in the preceding three months; neuropsychological problems; body mass index.

GNRI: ${ }^{(10) .}$

The GNRI formula results calculated as follow.

GNRI $=[1.489 \mathrm{X}$ albumin $(\mathrm{g} / \mathrm{L})]+$ [41.7 X (weight/WLo)]

GNRI defines 4 grades of nutritionrelated risk: major risk $(\mathrm{GNRI}<82)$, moderate risk (GNRI: 82 to $<92$ ), low risk (GNRI: 92 to $\leq 98$ ), and no risk (GNRI: <98).

\section{The Malnutrition Universal Screening Tool (MUST): ${ }^{(2)}$ derives a} score classifying malnutrition risk as low, medium or high on the basis of three components-BMI, history of unexplained weight loss and acute illness effect.

The patient-generated-subjective global assessment (PG-SGA) ${ }^{(8)}$ was adapted from the SGA. It includes additional questions regarding the presence of nutritional symptoms and short-term weight loss. It was designed so that the components of the medical history can be completed by the patient using a check box format. The physical examination is then performed by a health professional. 
Ethical considerations

The study methodology was reviewed and approved by the Research Review Board of the Geriatrics and Gerontology Department, Faculty of medicine, Ain Shams University.

Table 1: The scoring of the nutritional screening tools in the 2 groups

\begin{tabular}{|c|c|c|c|}
\hline & $\begin{array}{l}\text { Patients } \\
\text { with risk } \\
\text { of } \\
\text { malnutriti } \\
\text { on }\end{array}$ & $\begin{array}{l}\text { Patients } \\
\text { with } \\
\text { normal } \\
\text { nutrition } \\
\text { al status }\end{array}$ & $\begin{array}{l}P \\
\text { valu } \\
e\end{array}$ \\
\hline age & $64.7 \pm 5.8$ & $61.8 \pm 3.7$ & 0.23 \\
\hline $\begin{array}{l}M N A \\
\text { SF } \\
\text { score }\end{array}$ & $9 \pm 1.8$ & $12.5 \pm 0.7$ & $\begin{array}{l}0.00 \\
0\end{array}$ \\
\hline $\begin{array}{l}\text { MUS } \\
T \\
\text { score }\end{array}$ & $1.9 \pm 1.2$ & $0.6 \pm 0.9$ & 0.02 \\
\hline $\begin{array}{l}P G \\
\text { SGA } \\
\text { score }\end{array}$ & $6.5 \pm 3.5$ & $3.2 \pm 2.6$ & $\begin{array}{l}0.03 \\
6\end{array}$ \\
\hline $\begin{array}{l}\text { NRS } \\
\text { score }\end{array}$ & $3 \pm 1.8$ & $1.5 \pm 1.7$ & $\begin{array}{l}0.04 \\
7\end{array}$ \\
\hline $\begin{array}{l}\text { GNR } \\
\text { I } \\
\text { score }\end{array}$ & $85.3 \pm 8.7$ & $94.3 \pm 3.9$ & $\begin{array}{l}0.01 \\
4\end{array}$ \\
\hline
\end{tabular}

\section{Statistical methods:}

The collected data were coded, tabulated, revised and statistical analyzed using SPSS program (version 16). Quantitative variables were presented in the form of means and standard deviation. Qualitative variables were presented in form of frequency tables (number and percent).The comparison between quantitative variables was done using t-test. Pearson's correlation coefficient was used for parametric correlations. Receiver operating characteristic (ROC) curves were constructed. The area under each ROC curve was calculated to assess the discriminatory ability of the assessed tools to detect the risk of malnutrition.

Table 2: the correlation of different nutritional screening tools scores and MNA SF scoring:

\begin{tabular}{lll}
\hline & r & P value \\
\hline MUST score & -0.72 & 0.000 \\
$\begin{array}{l}\text { PG SGA } \\
\text { score }\end{array}$ & -0.63 & 0.003 \\
NRS score & -0.555 & 0.011 \\
GNRI score & 0.79 & 0.000 \\
\hline
\end{tabular}

Results:

The study included 20 participants $11(55 \%)$ females and 9(45\%) males. All of the participants were $\geq 60$ years old with mean age $63.6 \pm 5.1$ years (range 60-75 years).

The patients were categorized based on MNA SF results into 2 groups those with normal nutritional status 8 patients $(40 \%)$ and those with high risk of malnutrition 12 patients $(60 \%)$ of the studied sample.

The mean age of patients at risk of malnutrition was higher than those with normal nutritional status (64.7 years vs.61.8 years) yet of no statistical significance.

Table 1 show that there was significant difference between the two groups regarding each nutritional screening tools score.

The MUST, GNRI scores correlated better with MNA SF score than the NRS, PGSGA scores did $(r=-.072$, $0.79)$ and $(\mathrm{r}=-.0555,-0.63)$ respectively (table 2).

Table 3 shows that NRS had the highest sensitivity while GNRI had the 
highest specificity among different studied assessment tools.

Table 4 shows that using MUST and NRS together had better sensitivity $92.8 \%$ and specificity $66.6 \%$ with accuracy $85 \%$, using NRS and GNRI together had sensitivity $91.6 \%$ and specificity $50 \%$ with accuracy $75 \%$ ,other tools showed high sensitivity but low specificity as PGSGA with NRS and PGSGA and GNRI

Table 5 and figure 1 show that GNRI had the highest area under curve (0.828) showing the highest specificity.

Table 3: the sensitivity, specificity and accuracy of each screening tool:

\begin{tabular}{llll}
\hline tool & $\begin{array}{l}\text { Sensitiv } \\
\text { ity }\end{array}$ & $\begin{array}{l}\text { Specific } \\
\text { ity }\end{array}$ & $\begin{array}{l}\text { Accura } \\
\text { cy }\end{array}$ \\
& $\%$ & $\%$ & $\%$ \\
\hline $\begin{array}{l}\text { MUS } \\
\text { T }\end{array}$ & 83 & 62 & 75 \\
\hline PGSG & 83 & 12.5 & 55 \\
A & & & \\
\hline NRS & 91 & 50 & 75 \\
\hline GNRI & 66 & 75 & 70 \\
\hline
\end{tabular}

\section{Discussion:}

The goal of the current study was to compare the accuracy of different widely used nutritional screening tools in a sample of 20 consecutively hospitalized elderly patients.

Mini Nutritional Assessment is the tool recommended by European Society of Parenteral and Enteral Nutrition guidelines for screening and grading malnutrition ${ }^{(5)}$.
MNA-SF and NRS categorize patients into two categories of nutritional status: not at risk of malnutrition and at risk of malnutrition. However, MUST and PG SGA categorize patients into three categories of nutritional status: not at risk of malnutrition, at moderate risk of malnutrition and at severe risk of malnutrition. GNRI categorizes patients into 4 groups: severe risk, moderate risk, low risk, and those with no risk. For comparison reasons, the three risk categories of MUST and the four risk categories of GNRI were combined into two risk categories like in Raslan's study ${ }^{(11)}$.

Those with normal nutritional status accounted for $40 \%$ of the studied sample while those with high risk of malnutrition accounted for $60 \%$ of the studied sample.

This agrees with multiple previous studies that proposed hospitalization as a major predictor of malnutrition in elderly population ${ }^{(12)(13)(14)}$.

The MUST, NRS, GNRI, and PG-SGA scores not only were able to discriminate between the two categories, but they also correlated well with MNA SF score.NRS had the highest sensitivity $91 \%$ while specificity $50 \%$ with accuracy $75 \%$ then MUST sensitivity $83 \%$ and with specificity higher than NRS $62 \%$ and accuracy $75 \%$ then PGSGA had same sensitivity as MUST but less specificity and accuracy.

This is in line with previous studies: Neelemaat et al., 2011 who reported that NRS was found to have higher sensitivity (62\%) and specificity (93\%) than MUST (sensitivity 61\%, specificity $76 \%$ ) and NRI (sensitivity $43 \%$, specificity $89 \%$ ), compared with SGA $^{(15)}$.Moreover, Raslan et al., 2009 reported that NRS was the best yield 
for predicting unfavorable clinical

Table 4: the sensitivity, specificity and outcomes ${ }^{(11) \text {. }}$ accuracy of the combined screening tools:

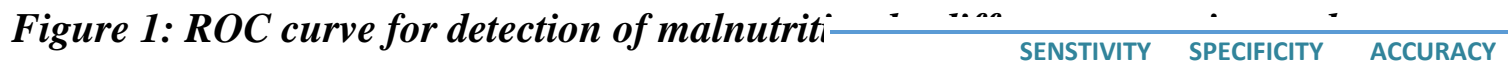

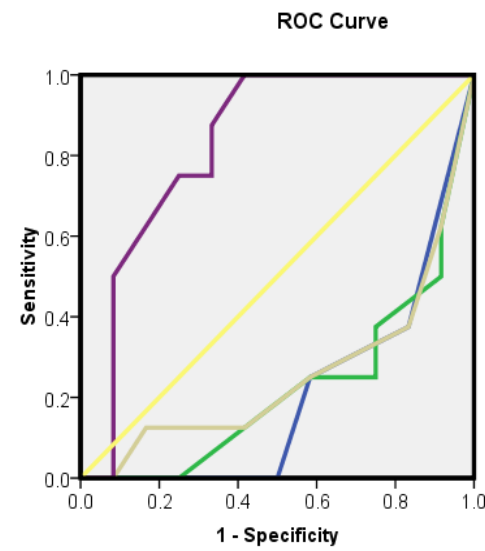

\begin{tabular}{|cccc|}
\hline $\begin{array}{r}\text { MUST + } \\
\text { PGSGA }\end{array}$ & 83.3 & 62.5 & 75 \\
\hline $\begin{array}{r}\text { MUST + } \\
\text { NRS }\end{array}$ & 92.8 & 66.6 & 85 \\
\hline $\begin{array}{r}\text { MUST + } \\
\text { GNRI }\end{array}$ & 83.3 & 62.5 & 75 \\
\hline $\begin{array}{r}\text { PGSGA } \\
\text { +NRS }\end{array}$ & 100 & 12.5 & 65 \\
\hline $\begin{array}{r}\text { PGSGA + } \\
\hline\end{array}$ & 100 & 12.5 & 65 \\
\hline
\end{tabular}

Table 5: Area under curve for each screening tool:

\begin{tabular}{ll}
\hline Tool & $\begin{array}{l}\text { Area } \\
\text { curve }\end{array}$ \\
\hline MUST score & 0.203 \\
PG SGA score & 0.224 \\
NRS score & 0.255 \\
GNRI score & 0.828 \\
\hline
\end{tabular}

Most of the studies agreed that GNRI is a simple, easy and valid tool in assessing malnutrition in elderly and in hospitalized elderly. Advantages of the GNRI are the low level of participation required from patients and subsequent exclusion of bias associated with past unintentional weight loss investigations ${ }^{(7)(16) .}$

In the current study, the sensitivity of GNRI was $66 \%$ and specificity $75 \%$ while Szeto, Kwan et al., $201{ }^{(17)}$ found the sensitivity and specificity of GNRI in predicting malnutrition to be $68.0 \%$ and $67.7 \%$ even when using another reference test (SGA).

The current study found PG-SGA to have sensitivity $83 \%$ and specificity $12.5 \%$ while in another study of Bauer et al., 2002 its sensitivity was $98 \%$ and the specificity was $82 \%{ }^{(18)}$. low specificity in the current study may be due to small sample size, lack of confirmatory laboratory investigations as reference test.

Many studies compared combining nutritional screening tools to different anthropometric or laboratory markers of malnutrition ${ }^{(19)(20),}$ but to our knowledge the current study is the only one assessed the effect of using different nutritional screening tools combinations on increasing their accuracy. 
The sensitivity of using both NRS and GNRI together increased to be $92.8 \%$ with specificity of $66.6 \%$ and accuracy of $85 \%$. So, using MUST and NRS together added little to the sensitivity of NRS alone. As a result NRS is considered the optimal screening tool for malnutrition in elderly hospitalized patients.

\section{Conclusion:}

NRS had the highest sensitivity while GNRI had the highest specificity among different studied assessment tools. MUST and NRS together had better sensitivity but lower specificity than either tool alone. We recommend Disclosure:

The author(s) declared no conflicts of interest with respect to the authorship and/or publication of this article.

\section{References:}

1. Stratton RJ, Green CJ, Elia M., (2003): Disease Related Malnutrition: an Evidence Based Approach to Treatment. Oxford: CABI.

2. Elia M., (2003): Screening for Malnutrition: Multidisciplinary

Responsibility. Development and use of the 'Malnutrition Universal Screening Tool' ('MUST') for Adults. BAPEN.

3. Cheskin LJ and Mitchell AM., (2003): Review: oral protein and energy supplements reduce all-cause mortality in elderly persons. ACP J Club; 138(3):59.

4. Berner YN. (2003): Review Assessment tools for nutritional status in the

8. Ottery FD (1994): Rethinking nutritional support of the cancer patient: the new field of nutritional oncology. Sem. Oncol. 21,770 - 778 . using NRS for malnutrition screening in elderly hospitalized patients

\section{Limitations of the study:}

A principal limitation of our study was that we compared all nutritional screening tools with the MNA SF, which is widely recommended, but is not regarded as the gold standard measure of malnutrition diagnosis.

\section{Funding:}

This research received no specific grant from any funding agency in the public, commercial, or not-for-profit sectors

elderly. Isr Med Assoc J; 5(5):365-7.

5. Kondrup J, Allison SP, Elia M, Vellas B, Plauth M, Educational and Clinical Practice Committee, European Society of Parenteral and Enteral Nutrition (ESPEN).,(2003): $\quad$ ESPEN guidelines for nutrition screening 2002.ClinNutr; 22(4):415-21.

6. Wells J. L\& Dumbrell A.C: Nutrition and aging: assessment and treatment of compromised nutritional status in frail elderly patients; Clinical Interventions in Aging 2006:1(1) 67-79.

7. Bouillanne O, Morineau G, Dupont C, Coulombel I, Vincent JP, Nicolis I, et al. Geriatric Nutritional Risk Index: a new index for evaluating at-risk elderly medical patients. Am J Clin Nutr 2005;82: 777-783.

9. Rubenstein LZ, Harker JO, Salva A, Guigoz Y, Vellas B. Screening for Undernutrition in Geriatric Practice: Developing the Short-Form Mini Nutritional Assessment (MNA- 


\section{Egyptian Journal of Geriatrics and Gerontology \\ March 2014 Volume 1(1)}

SF). J. Geront 2001; 56A: M366-377.

10. - Pablo AM, Izaga MA, Alday LA. Assessment of nutritional status on hospital admission: nutritional scores. Eur J Clin Nutr 2003;57:824-31.

11. Raslan M, Gonzalez MC, Goncalves Dias MC, Nascimento M, Castro M, Marques $\mathrm{P}$, Segatto $\mathrm{S}$, Torrinhas RS, Cecconello I \& Waitzberg DL.Comparison of nutritional risk screening tools for predicting clinical outcomes in hospitalized patients.Nutrition:2009; 26, 721-726.

12. Gariballa SE, Sinclair AJ. Nutrition, ageing and ill health. Br J Clin Nutr 1998;80:7-23

13. Bauer JM, Sieber CC: Significance and diagnosis of malnutrition in the elderly. $\mathrm{Z}$ Arztl Fortbild Qualitatssich 2007, 101(9):605-9.

14. Cuyac Lantigua M, Santana Porbán S: The Mini Nutritional Assessment of the elderly in the practice of a hospital geriatrics service: inception, validation and operational characteristics. Arch Latinoam Nutr 2007, 54(3):255-65.

15. Neelemaat F, Meijers J, Kruizenga $\mathrm{H}$, van Ballegooijen $H$, van Bokhorstde $M$, de van der Schueren B. Comparison of five malnutrition screening tools in one hospital inpatient sample. J Clin Nurs 2011; 20: 2144-2152.

16. Cereda E, Pedrolli C. The geriatric nutritional risk index. Curr Opin Clin Nutr Metab Care. 2009;12:1-7.

17. Szeto CC, Kwan BC, Chow KM, Law MC, Li PK. Geriatric nutritional risk index as a screening tool for malnutrition in patients on chronic peritoneal dialysis. J Ren Nutr. 2010;20:2937

18. BauerJ, Capra S and Ferguson M. Use of the scored PatientGenerated Subjective Global Assessment (PG-SGA) as a nutrition assessment tool in patients with cancer .European Journal of Clinical Nutrition. 2002:56, $779-785$.

19. Almeida AI, Correia M, Camilo M, Ravasco P. Nutritional risk screening in surgery: valid, feasible, easy!. Clin Nutr. 2012;31:206-211

20. Kyle UG, Kossovsky MP, Karsegard VL, Pichard C. Comparison of tools for nutritional assessment and screening at hospital admission: a population study. Clin Nutr. 2006; 25:409-417. 